[Agr. Biol. Chem., Vol. 33, No. 5, p. 771 780, 1969]

\title{
L-Glutamic Acid Fermentation
}

\section{Part VII. Relation between Biotin and Oleic Acid*}

\author{
By Toshihiko KanzakI, Kazuko Isobe, Hisayoshi OKazakI \\ and Hideo Fukuda \\ Research and Development Division, \\ Takeda Chemical Industries, Ltd., Osaka \\ Received October 7, 1968
}

\begin{abstract}
Relation between biotin and oleic acid was studied using a biotin-requiring organism accumulating L-glutamic acid and its blocked mutants lacking the biosynthetic system of biotin or/and oleic acid. The results support the following considerations. Biotin is not formed from oleic acid and does not substantially affect the growth of L-glutamic acidaccumulating bacteria and their productivity of L-glutamic acid.

Consequently, biotin serves only for the synthesis of fatty acids in the present organisms. The essential factor for their growth and metabolism is an unsaturated fatty acid like oleic acid and not biotin. And also, saturated fatty acids have substantially no relation with their growth and metabolism like accumulation of L-glutamic acid.
\end{abstract}

Previous works ${ }^{1,2)}$ have shown that mutation of a biotin-requiring organism accumulting $\mathrm{L}^{-}$ glutamic acid to an oleic acid-requiring mutant results in the loss of response to biotin showing only unsaturated fatty acid requirement, and that the mutant accumulates a large amount of L-glutamic acid irrespective of the amount of biotin in media.

Meanwhile, various approaches ${ }^{3281}$ to illustrate the biotin-replacing activity of oleic acid

\footnotetext{
* This work was presented at the Annual Meeting of the Agricultural Chemical Society of Japan, held at Nagoya, April 4, 1968.

1) T. Kanzaki, K. Isobe, H. Okazaki, K. Motizuki and H. Fukuda, Agr. Biol. Chem., 31, 1307 (1967).

2) H. Okazaki, T. Kanzaki, M. Doi, Y. Sumino and H. Fukuda, ibid., 31, 1314 (1967).

3) J. H. Mueller, S. Cohen and J.C. Snyder, J. Bact., 41, 581 (1941).

4) C. Nieman, Bact. Rev., 18, 147 (1954).

5) V. R. Williams and E. A. Fieger, J. Biol. Chem., 170, 399 (1947).

6) E. A. Andrews and V.R. Williams, ibid., 193, 11 (1951).

7) A. Traub and H. C. Lichstein, Arch. Biochem. Biophys., 62, 222 (1956).

8) S. Okumura, R. Tsugawa, T. Tsunoda and S. Motozaki, Nippon Nogeikagaku Kaishi, 36, 599 (1962).
}

in biotin-requiring organisms have been tried since the discovery ${ }^{31}$ in 1941 that oleic acid can be replaced for biotin for the growth of biotin-requiring organisms but detailed and full explanations about the relation between biotin and oleic acid appear to have not yet been reported.

Present investigation deals mainly with a substituting mechanism of oleic acid for biotin and roles of biotin in the L-glutamic acidaccumulating bacteria.

\section{MATERIALS AND METHODS}

Organisms. Following four microorganisms were used through this study; Brevibacterium thiogenitalis No. 653 (parent) as a biotin-requiring organism, D-248 $\left(\mathrm{OA}^{-}\right)$induced from No. 653 as an oleic acid-requiring organism, the mutant strain $\mathrm{DB}-2\left(\mathrm{DB}^{-}\right)$from No. 653 which grows in the presence of biotin but not in the presence of desthiobiotin, and an oleic acid-requiring mutant, $\mathrm{DBO}-12\left(\mathrm{DBO}^{-}\right)$from the $\mathrm{DB}^{-}$ strain.

Each mutant was obtained by means of ultraviolet. irradiation. 
Assay of biotin. Samples for biotin assay were prepared by neutralizing with $\mathrm{NaOH}$ after hydrolysis of a mixture of $2 \mathrm{ml}$ of $4 \mathrm{~N} \mathrm{H}_{2} \mathrm{SO}_{4}$ and $100 \mathrm{mg}$ of dry cells at $120^{\circ} \mathrm{C}$ for $90 \mathrm{~min}$.

Bioassay was carried out by the turbidimetric method using Saccharomyces cerevisiae ATCC 7754 and the medium described by $\mathrm{S}$. Okumura, R. Tsugawa, T. Tsunoda and S. Motozaki ${ }^{8}$ under a stationary condition.

The yeast used here was a biotin-requiring organism and its growth was not affected within the oleic acid concentration of $20 \mu \mathrm{g} /$ tube. A further progressive increase in oleic acid concentration brought about a corresponding inhibitory effect on the growth.

Analysis of fatty acids. A modification of the method of A.G. Marr and J.L. Ingraham, ${ }^{9}$ already descrided, ${ }^{101}$ was used.

Measurement of acetyl CoA carboxylase activity. Cells were harvested and washed by centrifugation. Cellfree extracts were prepared by grinding $3 \mathrm{~g}$ of wet cells with alumina in the presence of reduced glutathione ( $1 \mu$ mole per $\mathrm{g}$ of wet cells) under a stream of $\mathrm{N}_{2}$ and cooling by a freezing mixture. Extraction was made with approximately three parts of $0.02 \mathrm{M}$ phosphate buffer ( $\mathrm{pH} 7.0$ ) containing $1 \mathrm{mM}$ of reduced glutathione and the mixture was centrifuged at 15,000 $\times g$ for $15 \mathrm{~min}$. After the supernatant fluid was saturated to $40 \%$ with powdered ammonium sulfate and centrifuged, the resulting precipitate was collected and dissolved in $10 \mathrm{ml}$ of phosphate buffer mentioned above. After three to four successive operations of this procedure, the precipitate was dissolved in $4 \mathrm{ml}$ of the aforementioned buffer to use as an enzyme solution which contained usually about $10 \mathrm{mg} / \mathrm{ml}$ of protein.

Reaction was made by a modified method of $M$. Waite and S.J. Wakil.11 An incubation mixture $(0.55 \mathrm{ml})$ containing $78 \mathrm{~m} \mu$ moles of acetyl CoA, 1 $\mu$ mole of ATP, $30 \mu$ moles of potassium phosphate buffer ( $\mathrm{pH} 6.5$ ), $0.3 \mu$ moles of $\mathrm{MnCl}_{2}, 21 \mu$ moles of isocitrate, $5 \mu$ moles of $\mathrm{NaHC}^{\mathbf{1 4}} \mathrm{O}_{3}(5 \mu \mathrm{Ci})$ and $0.2 \mathrm{ml}$ of the enzyme solution was allowed to stand for 15 min, at $37^{\circ} \mathrm{C}$. The incubation mixture had been treated with $\mathrm{N}_{2}$ gas before $\mathrm{NaHC}^{14} \mathrm{O}_{3}$ was added

9) A.G. Marr and J.L. Ingraham, J. Bact., 84, 1260 (1962).

10) H. Okazaki, T. Kanzaki, A. Sugawara and H. Fukuda, Agr. Biol. Chem., 31, 1410 (1967).

11) M. Waite and S. J. Wakil, J. Biol. Chem., 237, 2750 (1962). finally.

The protein was centrifuged off by adding $0.05 \mathrm{ml}$ of $2 \mathrm{~N}^{-\mathrm{HClO}_{4}}$ to the incubated mixture, and the resulting supernatant fluid was made alkaline with 0.2 $\mathrm{ml}$ of $2 \mathrm{~N} \mathrm{KOH}$ and kept for $10 \mathrm{~min}$ at $100^{\circ} \mathrm{C}$. The alkaline solution was acidified to $\mathrm{pH} \mathrm{I}$ to 2 with $2 \mathrm{~N}$ $\mathrm{HClO}_{4}$ and then a $\mathrm{KCl}$ solution was added to exclude $\mathrm{ClO}_{4}^{-}$and subjected to centrifugation. The clear solution was evaporated to dryness and the residue was extracted with $1 \mathrm{ml}$ of ethanol. All of the extract was concentrated and submitted to ascending thin layer chromatography on a silica gel plate (Eastman Chromagram Sheet No. 6061) using the solvent system, $n$-butanol-formic acid-water $(4: 1: 2) .12$ ) Radioactivity was scanned by a Nuclear-Chicago Actigraph II Model C-100. Detection of organic acids was made by spraying xylose-aniline reagent. ${ }^{13)}$

Measurement of pyruvate carboxylase activity. Cells were harvested, washed and a $5 \%$ (on wet basis) suspension was prepared. After cells were disrupted by a sonic treatment at $20 \mathrm{Kc}$ for $10 \mathrm{~min}$, the resulting solution was centrifuged and the supernatant was used as an enzyme solution. Both of the enzyme solutions made from the cells of the four strains and from those of Proteus morganii IFO 3848 contained 5 to $6 \mathrm{mg} / \mathrm{ml}$ of protein.

Reaction was carried out according to a modified method of J. P. Kaltenbach and G. Kalnitsky. ${ }^{14}$ ) An incubation mixture $(3 \mathrm{ml})$ consisted of $150 \mu$ moles of pyruvate, $750 \mu$ moles of $\mathrm{KHCO}_{3}, 15 \mu$ moles of $\mathrm{MgCl}_{2}$, $15 \mu$ moles of ATP and $2 \mathrm{ml}$ of the enzyme solution. Before incubation, gas phase in the reaction tubes was replaced by $\mathrm{N}_{2}$ gas and they were incubated for 60 min at $35^{\circ} \mathrm{C}$. Reaction products were analyzed by ascending paper chromatography using Whatman No. 1 filter paper. The paper chromatogram was developed for 30 to $60 \mathrm{~min}$ with $n$-butanol-formic acid (95:5), water saturated.15।

Detection of radioactive biotin and desthiobiotin. Paper chromatographic technique (Whatman No. 1) was employed for the separation of biotin and desthiobiotin

12) M. Kusunose, E. Kusunose, $Y$. Kowa and $Y$. Yamamura, $J$. Biochem., 46, 525 (1959).

13) "Chromatographic Techniques" ed. by I. Smith, William Heinemann Medical Books Ltd., London, 1958 , p. 208.

14) J.P. Kaltenbach and G. Kalnitsky, J. Biol. Chem., 192, 629 (1951),

15) B. Magasanik and H. E. Umberger, J. Am. Chem. Soc., 72, 2308 (1950). 
using ascending method with $n$-butanol- $1 \mathrm{~N} \mathrm{HCl}(6: 1) .^{16}$ Detection and measurement of radioactivity were performed by an Aloka Thin Layer Chromatogram Scanner TRM-IB and a Packard Tri-Carb Liquid Scintillation Spectrometer, respectively.

Culture. The composition of the basal medium used for shake culture was as follows; $20 \mathrm{~g}$ or $100 \mathrm{~g}$ of glucose, $3.0 \mathrm{~g}$ of urea, $2.0 \mathrm{~g}$ of ammonium sulfate, $0.5 \mathrm{~g}$ of $\mathrm{KH}_{2} \mathrm{PO}_{4}, 0.5 \mathrm{~g}$ of $\mathrm{K}_{2} \mathrm{HPO}_{4}, 0.4 \mathrm{~g}$ of $\mathrm{MgSO}_{4} \cdot 7$ aq., $0.1 \mathrm{~g}$ of $\mathrm{FeSO}_{4} \cdot 7$ aq., $0.01 \mathrm{~g}$ of $\mathrm{MnSO}_{4} \cdot \mathrm{n}$ aq., 0 or $0.3 \mathrm{~g}$ of $\mathrm{CaCl}_{2} \cdot 2 \mathrm{aq}$., $200 \mu \mathrm{g}$ of thiamine hydrochloride and $1 \mathrm{ml}$ of the trace element solution were dissolved in 1 liter of distilled water. The trace element solution consisted of $88 \mathrm{mg}$ of sodium tetraborate, $37 \mathrm{mg}$ of ammonium molybdate, $8.8 \mathrm{mg}$ of $\mathrm{ZnSO}_{4} \cdot 7 \mathrm{aq} ., 270 \mathrm{mg}$ of $\mathrm{CuCl}_{2} \cdot 2$ aq. and 1 liter of distilled water. The usual oleic acid medium contained $300 \mu \mathrm{g}$ per $\mathrm{ml}$ of oleic acid in the basal medium mentioned above.

For the growth 1est, the $20 \mathrm{~g} /$ liter glucose medium was used and the $100 \mathrm{~g} /$ liter glucose medium was used for fatty acid analysis and such experiments as related to biotin behavior and L-glutamic acid fermentation.

When cultivation was carried out in the absence of oleic acid, $\mathrm{CaCl}_{2}$ was removed from the medium and vice versa.

Biotin measurement in the course of subculture for the growth test was performed by cultivating the corresponding subculture in the $100 \mathrm{~g} /$ liter glucose medium.

In the case of the growth test, $5 \mathrm{ml}$ of the medium was poured into a test tube and was inoculated with one loopful of cells grown on an agar slant with a synthetic medium without biotin, and incubated on a reciprocal test tube shaker at $28^{\circ} \mathrm{C}$ for two days.

As regard to the cultivation for fatty acid analysis, biotin measurement and L-glutamic acid fermentation, the following method was employed.

Seed cultures were grown in $20 \mathrm{ml}$ of the $20 \mathrm{~g} /$ liter glucose medium in $200 \mathrm{ml}$ conical flasks inoculated with cells on the aforementioned agar slant on a 200 rpm rotary shaker at $28^{\circ} \mathrm{C}$ for 24 to $48 \mathrm{hr}$. Main cultures were grown in $70 \mathrm{ml}$ of the medium poured into $200 \mathrm{ml}$ creased flasks on the rotary shaker at $32^{\circ} \mathrm{C}$ for two to four days.

16) K. Ogata, T. Tochikura, S. Iwahara, K. Ikushima, S. Takasawa, M. Kikuchi and A. Nishimura, Agr. Biol. Chem., 29, 895 (1965).
Growth was indicated by optical density of the cell suspension at $590 \mathrm{~m} / \mathrm{p}$ prepared by diluting the culture broth ten fold with distilled water.

Cells for assay of acetyl CoA carboxylase and pyruvate carboxylase activities were also obtained by the same method as mentioned above. Each enzyme solution was prepared using cells at maximum growth.

Proteus morganii IFO 3848 was cultivated in the medium composed of $0.1 \%$ of Bacto-peptone (Difco), $0.2 \%$ of Bact-yeast extract (Difco), $0.05 \%$ of beef extract (Wako), $0.1 \%$ of $\mathrm{KCl}, 0.12 \%$ of $\mathrm{K}_{2} \mathrm{HPO}_{4}$, $0.03 \%$ of $\mathrm{KH}_{2} \mathrm{PO}_{4}$ and $5 \%$ of glucose at $30^{\circ} \mathrm{C}$ for $18 \mathrm{hr}$ on the rotary shaker.

Chemicals. Oleic, palmitoleic and petroselinic acids were the products of Nutritional Biochemical Cooperation, and their purities were analyzed to be more than $99 \%$. Vaccenic acid was purchased from Tokyo Chemicals Co. Ltd. and its purity was 90\%. Each acid was as a sodium salt.

Avidin (3300 U/g) was also purchased from Nutritional Biochemical Cooperation.

\section{RESULTS AND DISCUSSION}

Effect of various compounds on the growth of the four strains

In order to examine the relation between biotin and oleic acid, in the beginning, responses of the four strains to biotin, desthiobiotin, oleic and pimelic acids were investigated. The results in Table I show that the

TABle I. GROWTH Responses of PARENT AND MUTANT STRAINS TO BIOTIN,DESTHIOBIOTIN, Oleic AND PIMELIC ACID

\begin{tabular}{lccccc}
\multicolumn{1}{c}{$\begin{array}{c}\text { Strain } \\
\text { Supplement }\end{array}$} & Parent & $\mathrm{DB}^{-}$ & $\mathrm{OA}^{-}$ & $\mathrm{DBO}-$ \\
Biotin & $30 \mu \mathrm{g} / \mathrm{liter}$ & $0.52^{*}$ & 0.49 & 0.02 & 0.02 \\
Desthiobiotin $30 \mu \mathrm{g} / \mathrm{liter}$ & 0.48 & 0.02 & 0.02 & 0.02 \\
Oleic acid $300 \mu \mathrm{g} / \mathrm{ml}$ & 0.51 & 0.43 & 0.41 & 0.42 \\
Pimelic acid $500 \mu \mathrm{g} / \mathrm{ml}$ & 0.11 & 0.02 & 0.02 & 0.02
\end{tabular}

* Optical density.

parent strain grew on any medium supplemented with biotin, desthiobiotin, oleic and pimelic acids. The fact that the parent strain grew on desthiobiotin and pimelic acid suggests the presence of the biosynthetic pathway of biotin from pimelic acid via desthiobiotin as 
proposed by F. J. Ryan. ${ }^{17 !}$

$\mathrm{DB}^{-}$strain was able to grow on biotin but not on desthiobiotin. Considering the biosynthetic pathway proposed by F. J. Ryan ${ }^{171}$ and S. Okumura, R. Tsugawa, T. Tsunoda and S. Motozaki, ${ }^{18)} \mathrm{DB}^{-}$was thought to be a mutant blocked between desthiobiotin and biotin. Further, as $\mathrm{DB}^{-}$did not grow on pimelic acid, it is surmised that this mutant does not have the biosynthetic system of biotin from pimelic acid without passing through desthiobiotin as proved by A. Lezius, E. Ringelmann and F. Lynen. ${ }^{193}$

$\mathrm{OA}^{-}$and $\mathrm{DBO}^{-}$did not respond to compounds other than oleic acid and their responses to oleic acid were similar to each other.

\section{Subculture of the four strains on the oleic acid medium}

As described above, all the present strains showed growth responses to the same degree. To eliminate the possibility that the growth was due to substances other than oleic acid,

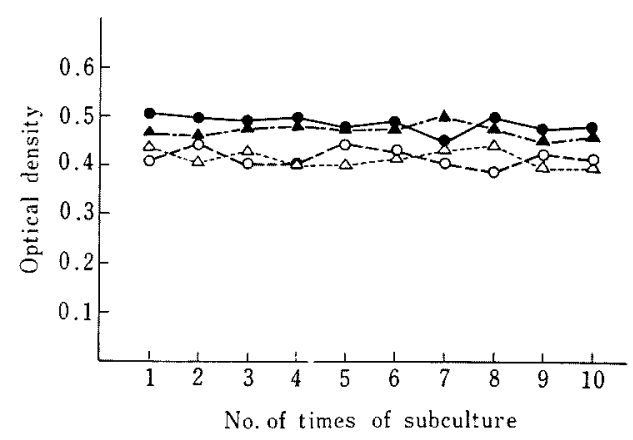

FIG. 1. Growth Changes of Parent and Mutant Strains by Subculturing on the Oleic Acid Medium.

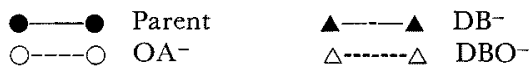

17) F.J. Ryan, Japanese Jourral of Genetics, 31, 266 (1956).

18) S. Okumura, R. Tsugawa, T. Tsunoda and S. Motozaki, Nippon Nogeikagaku Kaishi, 36, 605 (1962).

19) A. Lezius, E. Ringelmann and F. Lynen, Biochem. Z., 336, 510 (1963). a subculture method was tried.

As shown in Fig. 1, the degree of each growth did not change substantially after ten times of subculture.

These results therefore suggest the growth responses of these strains are only dependent on oleic acid.

Now, the fact that both $\mathrm{DB}^{-}$and $\mathrm{DBO}^{-}$, which are presumed to be the mutants blocked between desthiobiotin and biotin in the biosynthetic system of biotin, grew as well on oleic acid as the parent and $\mathrm{OA}^{-}$strains gives a negative ground against a hypothesis $\mathrm{s}^{6,18,20,21}$ that biotion may be synthesized from oleic acid via pelarogonic acid derivatives and desthiobiotin.

In addition, the growth was not affected even if oleic acid was treated with 1 unit of avidin per $\mathrm{mg}$ of the acid and the medium treated with 0.01 unit of avidin per $\mathrm{ml}$ of the medium was employed.

Consequently, it is reasonable to consider that the growth of the four strains on oleic acid has no relations to biotin.

\section{Biotin content in the subcultured broths}

If biotin could be synthesized from oleic acid, one can expect that it must be detected in the broths subcultured on the oleic acid medium without addition of biotin and its content would be constant during subculture.

Table II. Biotin Content IN the Subcultured BROTHS OF PARENT AND OA- STRAINS GROWN ON THE Oleic ACId MEdIUM*

$\begin{array}{ccc}\begin{array}{c}\text { Strain } \\ \text { No. of times of subculture }\end{array} & \begin{array}{c}\text { Parent } \\ \mathrm{m} \mu \mathrm{g} / \mathrm{ml}\end{array} & \begin{array}{c}\mathrm{OA}^{-} \\ \mathrm{m} \mu \mathrm{g} / \mathrm{ml}\end{array} \\ 1 & 0.08 & 0.08 \\ 5 & 0.08 & 0.08 \\ 10 & 0.08 & 0.08\end{array}$

* The composition of the oleic acid medium are shown in "Culture" among "Materials and Methods"

20) H. P. Broquist and E. E. Snell, J. Biol. Chem., 188, 431 (1951).

21) R.W. Thoma and W. H. Peterson, J. Bact., 60,39 (1950). 
Table II presents a change of biotin content in the subcultured broths pursued by means of the bioassay technique using Saccharomyces cerevisiae showing substantially no response to oleic acid. Biotin was not detectable by this bioassay method.

From the result in Table II, biotin content in the cells was calculated to contain approximately less than $27 \mathrm{~m} \mu \mathrm{g}$ of biotin per $\mathrm{g}$ of dry cells.

\section{Material balance of biotin during cultivation on the} oleic acid medium

A further investigation by another method was undertaken to confirm the impossibility of biotin formation from oleic acid.

Table III. Changes of Brotin Content in OACulture DuRing Cultivation

$\begin{array}{cccc}\text { Culture hour } & \begin{array}{c}\text { Biotin } \\ \text { concentration } \\ \mathrm{m} \mu \mathrm{g} / \mathrm{ml}\end{array} & \begin{array}{c}\text { Total } \\ \text { volume } \\ \mathrm{ml}\end{array} & \begin{array}{c}\text { Total } \\ \text { biotin } \\ \mathrm{m} \mu \mathrm{g}\end{array} \\ 0 & 0.60 & 525 & 315 \\ 48 & 0.61 & 507 & 309\end{array}$

The data in Table III suggest that biotin synthesis from oleic acid did not occur during the increase in cells since initial biotin content was at the same level as that when maximum growth was attained.

\section{Possibility of ${ }^{14} \mathrm{C}$-biotin formation from $U_{-}^{14} C$ - oleic acid}

After $\mathrm{OA}^{-}$culture was grown on $20 \mathrm{ml}$ of the medium containing $2.5 \mu \mathrm{Ci}$ of $\mathrm{U}^{-14} \mathrm{C}$-oleic acid (specific activity $100 \mu \mathrm{Ci} / 260 \mu \mathrm{g}$ ) and 300 $\mu \mathrm{g} / \mathrm{ml}$ of cold oleic acid for $24 \mathrm{hr}$, the cells were harvested and subjected to acid hydrolysis with $4 \mathrm{~N}_{2} \mathrm{SO}_{4}$ at $120^{\circ} \mathrm{C}$ for $90 \mathrm{~min}$. The hydrolysate was extracted with ethyl ether. An appropriate aliquot of each fraction was submitted to paper chromatography as indicated in the experimental methods.

The formation of ${ }^{14} \mathrm{C}$-biotin was not demonstrated as shown in Fig. 2. Though the same paper was cut off to small pieces and they
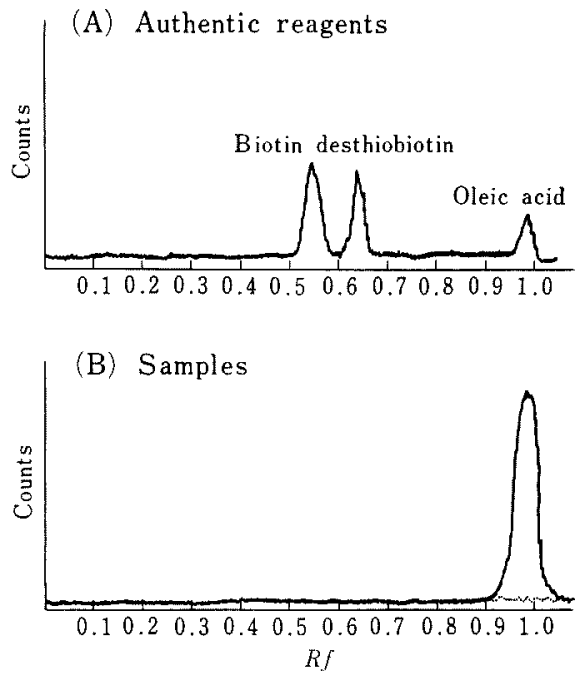

FIG. 2. Chromatograms of Products $\mathrm{OA}^{-}$Culture Incubated on U-14C-Oleic Acid.

Solvent system: $n$-butanol-1N $\mathrm{HCl}(6: 1)$

were subjected to the liquid scintillation spectrometer after the paper was analyzed by the chromatogram scanner, no radioactivity was detected on the area corresponding to biotin and desthiobiotin.

If biotin were only in the residue and had the same radioactivity as the back ground counts (about $20 \mathrm{cpm}$ ), total biotin synthesized was calculated to be at most $0.4 \mathrm{~m} \mu \mathrm{g}$ of biotin in $20 \mathrm{ml}$ of the culture even when biotin synthesis occurred from oleic acid.

Effect of various unsaturated fatty acids on the growth of the four strains

Pelargonic acid is produced from a fatty acid unsaturated at C-9 position by oxidation. Therefore, it is possible to assume that biotin may be formed from oleic acid having an unsaturated bond at 9 th position of carbon because the synthesis of biotin from pelargonic acid derivatives has been demonstrated in some microorganisms.

The present strains evidently grew on petroselinic and vaccenic acids which have 
not an unsaturated bond at C-9 position, though the degree of the growth was lesser than that on oleic and palmitic acids as in Table IV. Accordingly, it may be thought as

TABle IV. GRowth RESPONSES OF PARENT AND MUTANT STRains to Various FATTY ACIDS

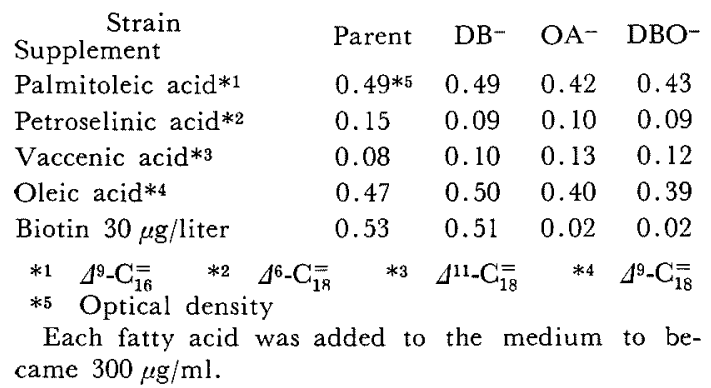

a circumstantial evidence of the independence of biotin for the growth on an unsaturated fatty acid that four strains could grow on petroselinic and vaccenic acids.

Now, the analysis of fatty acids in cells grown on palmitoleic acid demonstrated only hexadecenoic acid and no other fatty acid by the gas-liquid chromatography.

Fatty acid composition in cells grown on biotin or land oleic acid

Figure 3 presents patterns of fatty acid composition in cells grown on biotin or/and oleic acid.

In the presence of biotin, myristic, palmitic oleic and an unknown acids were detected in both parent and $\mathrm{OA}^{-}$strains as shown in Fig. $3(\mathrm{~A})$ and (B). There were no qualitative differences in fatty acid composition though some differences were observed quantitatively, e.g. in hexadecenoic and octadecenoic acid contents.

On the other hand, $\mathrm{OA}^{-}$cells grown on oleic acid contained only octadecenoic acid, presumably the added oleic acid, and didn't contain myristic and palmitic acids as observed in the presence of biotin as in Fig. $3(\mathrm{G})$. This relation was similar in the parent cells grown on oleic acid.

(A) Parent, biotin $30 \mu \mathrm{g} /$ liter added

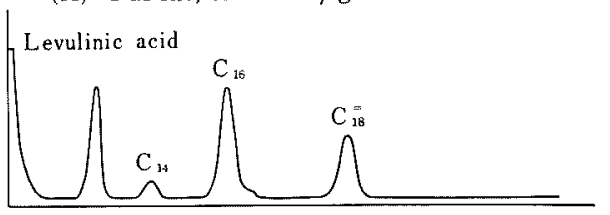

(B) $\mathrm{OA}^{-}$, biotin $30 \mu \mathrm{g} /$ liter and oleic acid $300 \mu \mathrm{g} / \mathrm{ml}$ added

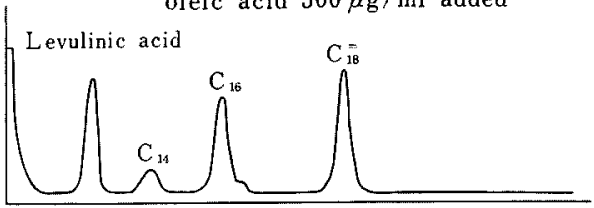

(C) $\mathrm{OA}^{-}$, oleic acid $300 \mu \mathrm{g} / \mathrm{ml}$ added

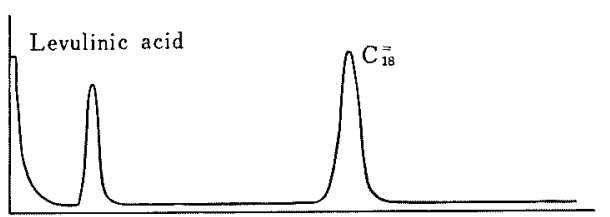

FIG. 3. Gas-liquid Chromatograms of Fatty Acids from Culture Cells Grown in the Presence of Biotin or/and Oleic Acid.

As for levulinic acid, it occurred by heat sterilization of media containing glucose. When glucose was sterilized separately, no levulinic acid was found in the cells but the growth and the fatty acid composition were not altered.

The data in Fig. 3 suggest that the lack in saturated fatty acid synthesis in cells grown on oleic acid was due to either the absence of biotin enzyme or its apparent inactivity due to the absence of biotin, provided that fatty acid synthesis takes place via malonyl CoA derived from acetyl $\mathrm{CoA}$ and $\mathrm{CO}_{2}$ by the action of acetyl CoA carboxylase, a biotin enzyme, as known well. ${ }^{11,22)}$

Effect of biotin and oleic acid on fatty acid composition and L-glutamic acid accumulation.

22) S.J. Wakil, J. Am. Chem. Soc., 80, 6465 (1958). 


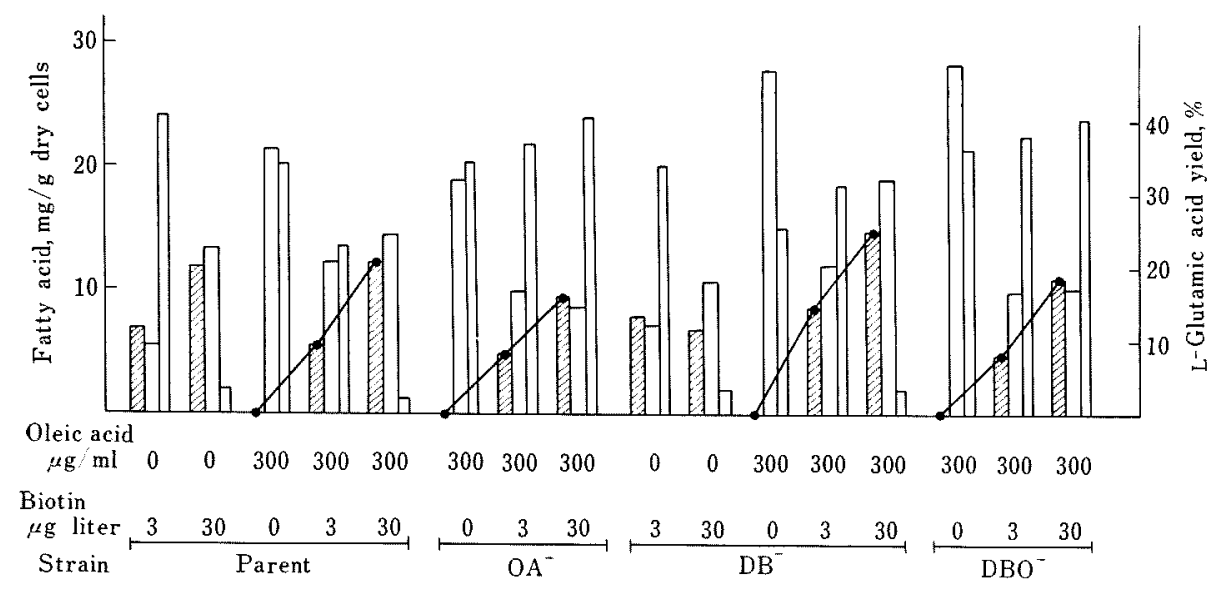

FIG. 4. Correlation among Palmitic, Oleic and L-Glutamic Acids in the Presence of Biotin or/ and Oleic Acid.

IIIIIIII $\mathrm{C}_{16} \square \mathrm{C}_{18} \square$ L-glutamic acid

Many workers ${ }^{23 \sim 27 !}$ have shown that biotin itself doesn't play any essential role in the accumulation of $\mathbf{L}$-glutamic acid and so a large amount of it is accumulated even if in the presence of an excess amount of biotin if an appropriate means is taken.

Here, further experiments to examine the correlation among biotin, cell fatty acids and L-glutamic acid accumulation, and meaning of biotin in the microorganisms were undertaken by changing the concentrations of biotin and oleic acid.

The data in Fig. 4 lead us to following explanations.

First, as regards fatty acid composition, palmitic acid content was found to be closely related to the amount of biotin added as linked with solid lines, i.e., palmitic acid was not

23) N.L. Somerson and T. Philips, Belg. Patent, No. 593807 (1961).

24) K. Udagawa, S. Abe and S. Kinoshita, J. Ferment. Tech., 40, 614 (1962).

25) I. Shiino, S. Ôtsuka and N. Katsuya, J. Biochem., 51, 56 (1962); idem., ibid., 52, 108 (1962); idem., ibid., 53, 333 (1963).

26) M. Shibukawa and T. Ohsawa, Agr. Biol. Chem., 30, 750 (1966).

27) T. Kanzaki, H. Okazaki, A. Sugawara and H. Fukuda, ibid., 31, 1416 (1967). observed when biotin was not added to the medium as shown in Fig. 3. This is thought to be a reflect of the absence of biotin in the cells as described above. On the other hand, a considerable amount of L-glutamic acid was accumulated regardless of strains in the medium without addition of biotin, where saturated fatty acids were not demonstrated in the cells.

The fact presented above gives a reasonable explanation for unessentiality of biotin to not only the microbial growth but the productivity of L-glutamic acid. Simultaneously, it also reveals that saturated fatty acids did not play an essential role in the microbial growth and L-glutamic acid accumulation.

\section{Measurement of acetyl CoA carboxylase activity}

Acetyl CoA carboxylase which requires biotin and catalyzes a part of fatty acid synthesis ${ }^{11,231}$ was tested to confirm further in vitro the biotin-fatty acid relations described above.

Figure 5 presents changes of acetyl CoA carboxylase activity using a protein fraction extracted from the cells of $\mathrm{OA}^{-}$strain grown on the oleic acid medium with or without 
(A)

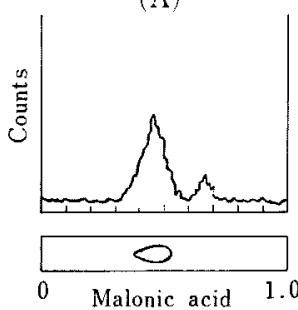

$R f$
(B)

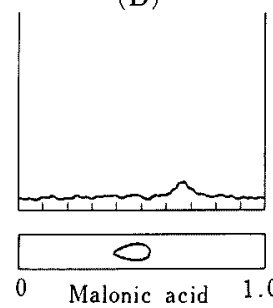

$R f$
(C)

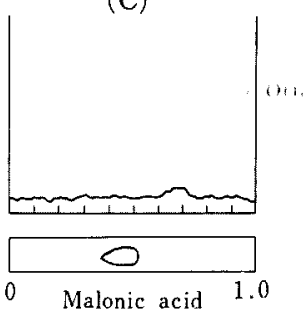

$R /$

FIG. 5. Thin Layer Chromatograms of Products from $\mathrm{NaH}^{14} \mathrm{CO}_{3}$ and Acetyl Coenzyme A by a Protein Fraction of OA- Strain.

Solvent system: $n$-butanol-formic acid-water ( $4: 1: 2$ )

In the experiment (A), $\mathrm{OA}^{-}$strain was cultivated in the presence of $10 \mu \mathrm{g} / \mathrm{liter}$ of biotin and $300 \mu \mathrm{g} / \mathrm{ml}$ of oleic acid. In (B) and (C), only oleic acid was added to the culture medium. In (C), $20 \mu \mathrm{g}$ of biotin was added to the reaction mixture.

supplementation of biotin.

The protein fraction derived from the cells grown on the biotin-oleic acid medium catalyzed the formation of a substance corresponding to malonic acid (Fig. 5(A)) which gave the same $R f$ value of 0.6 as malonic acid with the solvent system, ethanol-acetic acid-water $(12: 3: 1)$ on a Eastman Chromagram Sheet (silica gel) strip and so the substance will be called as malonic acid hereafter. Malonic acid, however, was not demonstrated in the case of the protein fraction from the cells grown without addition of biotin as shown in
Fig. 5(B).

In addition, it can be speculated that apoenzyme of acety CoA carboxylase itself was not produced in the cells grown on the oleic acid medium without addition of biotin since when biotin was added to the reaction mixture in the experiment (B) malonic acid did not formed.

\section{Effect of biotin and avidin on acetyl CoA carboxyl- ase activity}

Since it was uncertain whether the malonic acid-forming activity from acetyl CoA and
(A)

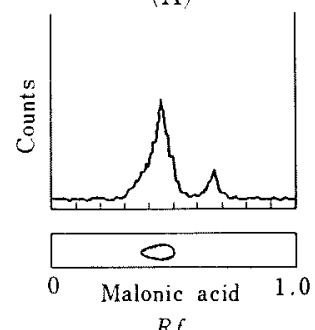

(B)

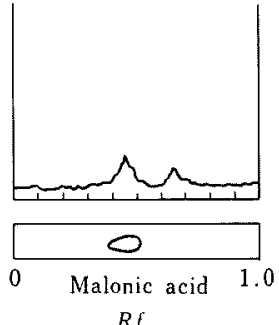

(C)

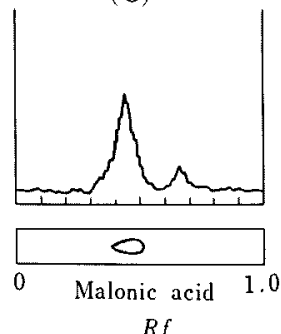

FIG. 6. Effect of Biotin and Avidin on the Formation of ${ }^{14} \mathrm{C}-\mathrm{Malonic}$ Acid from $\mathrm{NaH}^{14} \mathrm{CO}_{3}$ and Acetyl Coenzyme A by a Protein Fraction of $\mathrm{OA}^{-}$Strain.

In the experiments (A), (B) and (C), cultivation was carried out in the presence of $300 \mu \mathrm{g} / \mathrm{ml}$ of oleic acid. In (A), no supplement was added, but in (B), 1 unit of avidin was added to the reaction mixture. In (C), 1 unit of avidin and $20 \mu \mathrm{g}$ of biotin was added simultaneously to the mixture. Each reaction tube was allowed to stand for $10 \mathrm{~min}$ under room temperature to make react biotin with avidin before incubation. 
$\mathrm{CO}_{2}$ was dependent on biotin or not, it was necessary to make it clear.

Figure 6(A) shows a change of malonic acid-forming activity in the case of the protein fraction from the cells grown on the biotinoleic acid medium. As in Fig. 6(B), the amount of malonic acid formed was decreased considerably by the addition of avidin to the reaction mixture.

However, simultaneous addition of biotin in an excess amount to the avidin in the reaction mixture eliminated the negative effect of avidin as shown in Fig. 6(B) (Fig. $6(\mathrm{C})$ ).

Consequently, these results allow a reasonable speculation that the malonic acid formation from acetyl $\mathrm{CoA}$ and $\mathrm{CO}_{2}$ was due to acetyl CoA carboxylase, a biotin enzyme.

\section{Measurement of pyruvate carboxylase activity}

The experiment was followed by examining pyruvate carboxylase which is known as another biotin enzyme.

In both parent and $\mathrm{OA}^{-}$strains, oxaloacetic acid-forming activity from pyruvic acid and

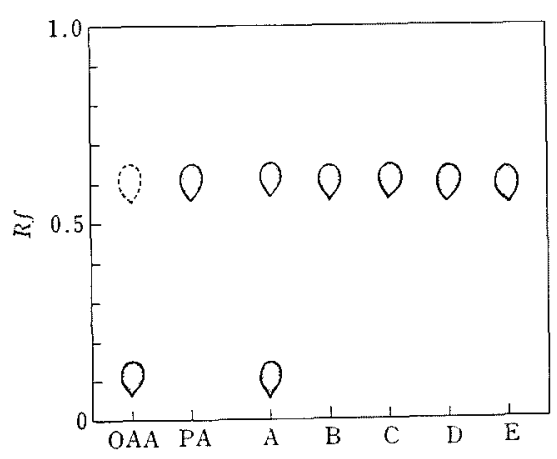

FIG. 7. A Paper Chromatogram of Products from Pyruvic Acid.

OAA: Authentic oxaloacetic acid

RA: Authentic pyruvic acid

A: Proteus morganii

B: Parent (Biotin $30 \mu \mathrm{g} /$ liter)

C: $\quad \mathrm{OA}^{-}$(Oleic acid $300 \mu \mathrm{g} / \mathrm{ml}$, biotin $30 \mu \mathrm{g} / \mathrm{liter}$ )

D: Parent (Oleic acid $300 \mu \mathrm{g} / \mathrm{ml}$ )

E: $\quad \mathrm{OA}^{-}$(Oleic acid $300 \mu \mathrm{g} / \mathrm{ml}$ )

Solvent system: $n$-butanol-formic acid (95:5), $\mathrm{H}_{2} \mathrm{O}$ satd.
$\mathrm{CO}_{2}$ was not observed despite of the presence of biotin in the culture medium under the tested conditions as shown in Fig. 7.

To confirm the result, a crude extract of Proteus morganii with pyruvate carboxylase ${ }^{14 !}$ was tested for the enzyme activity comparing with the L-glutamic acid-accumulating organisms.

Oxaloacetic acid formation was obviously demonstrated in the case of Proteus morganii as in Fig. 7. Oxaloacetic acid formed was also identified as a hydrazone compound by the method of O. Gavallini, N. Frontali and G. Toschi. ${ }^{291}$ These results suggest that pyruvate carboxylase does not concern the growth and L-glutamic acid accumulation in the present strains.

The results in this study demonstrated that all of organisms used here including the parent strain requiring biotin for its growth was capable of growing and playing metabolic activities like the accumulation of L-glutamic acid to the same extent as in the presence of biotin even if biotin was not added to the culture medium in case oleic acid was supplemented.

In other words, it seems most reasonable to conclude that biotin was no more than a cofactor for synthesizing fatty acids, and that the essential requirement in the present strains was an unsaturated fatty acid.

To date, many works have been reported about the biotin-replacing activity of oleic acid. They are tentatively able to be classified into three groups, as follows; (1) biotin is related with the fatty acid synthesis, ${ }^{29,30)}$ (2) biotin is or may be synthesized from oleic acid, ${ }^{6,8,201}$ (3) oleic acid is apparently substituted for biotin by stimulating the uptake of an extremely small amount of biotin in the medium into the cells." However, these leave room

28) D. Cavallini, N. Frontali and G. Toschi, Nature, 163, 568 (1949).

29) H. P. Broquist and E. E. Snell, J. Biol. Chem., 173, 435 (1948).

30) S. H. Rubin and J. Scheiner, Arch. Biochem., 23, 400 (1949). 
for some discussions.

In view of the present results, one might consider that if there are such organisms as those requiring biotin which grow on an unsaturated fatty acid medium free from biotin, in these organisms, biotin participates only in fatty acid synthesis, and that an unsaturated fatty acid is an essential factor for their growth and metabolism as for microorganisms used here. Among biotin-requiring microorganisms, there are also known microorganisms which do not respond to an unsaturated fatty acid. ${ }^{181}$ In such cases, either fatty acid uptake into cells may be impossible or some biotin enzymes other than acetyl CoA carboxylase may be indispensable factors for their growth, or they may require substances of which biosynthesis depends on biotin.
Finally, as for physiological roles of fatty acids, the present results also offer that unsaturated fatty acids should play essential roles in membrane functions, and that saturated fatty acids should have no relation with its functions because most of fatty acids in cells is contained in phospholipids which are distributed in membrane fraction of cells and also phospholipids play a leading role in membrane functions.

Acknowledgements. The authors are most grateful to Drs. S. Tatsuoka, R. Takeda and Y. Ishida for their helpful advices and discussions. They also wish to express their sincere thanks to Mr. A. Matsukura, Mrs. K. Yoshino and Miss M. Tanaka for the bioassay of biotin, and to Mr. T. Maei for his expert assistance. 